\title{
Initial Volume of Distribution
}

National Cancer Institute

\section{Source}

National Cancer Institute. Initial Volume of Distribution. NCI Thesaurus. Code C102371.

The initial volume of distribution for a substance administered by bolus intravascular dosing. 